\title{
Jens Andermann, Tierras en trance. Arte y naturaleza después del paisaje. Santiago de Chile, Metales Pesados, 2018, 462 páginas
}

\author{
Matías Di Benedetto
}

Cita sugerida: Di Benedetto, M. (2020).

[Revisión del libro Tierras en trance. Arte y naturaleza después del paisaje por J. Andermann]. Orbis Tertius, 25(32), e185. https://doi.org/10.24215/18517811e185

En la primera parte de una de las novelas latinoamericanas más importantes del llamado regionalismo, $\mathrm{La}$ vorágine de José Eustasio Rivera, se alude de manera peculiar a los emprendimientos extractivistas. El cauchero Barrera aparece en busca de los "enganchados" y con ese fin reparte entre el público una serie de "postales de colores". En ellas se retrata a los trabajadores acodados a los barandales de casas de dos pisos mientras observan las "lanchas de vapor [que] humeaban en el puertecito" (2002, p. 179). Estas fotografías funcionan como el "reverso del fulgor progresista" capaces de hilar una "(eco) historia alternativa de la modernidad” (2018, p. 178). A partir de la conflictiva relación entre el ambiente y los modos representativos, esta y otras ficciones regionalistas dejan entrever "un pensamiento ecológico y político que trabaja por dentro de las formas estéticas” (p. 28) y que sienta las bases para una aproximación literaria y artística al extractivismo ya que describen la transformación de los paisajes en tanto modalidad del despojo que subraya, ante todo, su carácter destructivo. De esta manera, la centralidad del regionalismo literario en la estructura general de Tierras en trance. Arte y naturaleza después del paisaje de Jens Andermann se apoya en la revelación no sólo de una genealogía del antropoceno que tiene su origen en dichas textualidades, las cuales forman parte de un conjunto de "constelaciones artísticas entre, aproximadamente, la década de 1920 y el presente" (p. 26), sino también como descripción de uno de los momentos destacados del "viraje" (p. 28) que se produce en el proceso estético del último siglo, representante de un "giro crítico" (p. 27) propio de la teoría cultural que describe las transformaciones conceptuales propias del paisaje en virtud de la aparición de la postnaturaleza como condición fundante de la era del antropoceno. Andermann, sin embargo, señala que su intención metodológica no busca reproducir lo que a las claras podría entenderse, si nos atenemos a la importancia otorgada a dicho capítulo central de su libro, como un "itinerario melancólico" (p. 425) hacia formas 
idealizadas del paisaje y el ambiente natural. Para ello refuerza la idea de que este es un "libro de trances" (p. 425). En esta noción el autor halla un procedimiento que "vuelve a ensamblar, en el inconsciente, el espacio y tiempo del sujeto y la comunidad, escindidos por una violenta historia de desplazamientos y rupturas temporales" (p. 22). De este modo, su objetivo es hacer foco en "nuevos agenciamientos y ensamblajes" (p. 22) artísticos, promotores de un "saber ver" (p. 25) (y nombrar) los rumores, las "palpitaciones" y "vibraciones" ocultas detrás del gran relato de la Historia, capaces de revelar una "gran pulsión antiépica" que busca acercar al hombre al mundo natural a través de una animalización del "tiempo domesticado de una historia puramente humana” (p. 433). Aunque, a decir verdad, lo que sí habrá en este libro es el despliegue constante de diversas geografías y de propuestas artísticas y literarias arraigadas a esos territorios.

El libro consta de una introducción, cinco capítulos y una conclusión. En el primer capítulo titulado "Viaje accidentado: vanguardia y velocidad" se aúna en una misma trama la fascinación por la técnica propia de algunas de las vanguardias históricas y su particular asimilación por parte de las manifestaciones rupturistas en Latinoamérica. La experiencia de la velocidad de este lado del Atlántico está ligada a una poética del accidente, representativa de "un tiempo narrativo y poético sincopado" capaz de dar cuenta de "experiencias de no simultaneidad incompatibles con el éxtasis futurista" (p. 36). Al respecto, Andermann profundiza en el trabajo de Serge Eisenstein durante la filmación de ¡Que viva México!, al comparar "la mesa de edición con el telar" (p. 41) en referencia directa al famoso encuentro fortuito sobre la mesa de disección de la máquina de coser y un paraguas de Los cantos de Maldoror de Lautréamont, imagen retomada luego por los surrealistas. Así, los contrastes violentos expuestos mediante el diseño textil del sarape emulan los puntos de contacto entre lo nuevo y lo arcaico que los fotogramas de Eisenstein reproducen a su manera. Al igual que el cineasta ruso recorriendo México, el punto de vista móvil del viajero moderno también organiza los aportes dedicados al viaje de Blaise Cendrars por Brasil. Andermann revisa la "conversación poética y plástica" (p. 58) que dicho escritor europeo tiene con Oswald de Andrade y Tarsila do Amaral cuya productividad radica en el redescubrimiento del paisaje que los rodea a partir de la adopción del punto de vista itinerante del turista. En relación con este tema, hay una importancia insoslayable en el rol que adquiere el automóvil en Latinoamérica a partir de su conceptualización como vector de integración nacional. A partir de travesías como las protagonizadas por Roger Courteville a bordo de su camionette Renault de seis ruedas o el emprendido por la periodista Ada Elflein rumbo a la Patagonia, el automóvil se convierte en la punta de lanza de un Estado que considera necesario para su proyecto moderno invertir en infraestructura vial. Esto permite, enfatiza el autor, una "reconversión turística del paisaje carretero" (p. 75) ligada indefectiblemente con la resignificación del viaje de la vanguardia, el cual abandona sus ínfulas bohemias para convertirse en un insumo de la "pedagogía turística" (p. 76). Sin embargo, quienes van a renegar de este despliegue de medios de transporte como estrategia de modernización del Estado liberal serán dos escritores anti-viajantes como Roberto Arlt y Mário de Andrade. Abocados a un trabajo periodístico que los encuentra a bordo de diferentes medios de transporte como un buque o un automóvil, tanto Arlt como Mário rechazan tanto la patrimonialización estatal del paisaje así como también ponen en crisis la naturalización del "acto de escribir andando" (p.79). Al enfatizar en las interrupciones y alejándose de la "co-presencia discontinua de elementos dispares" (p. 83) propuesta por Cendrars, Oswald o Eisenstein, ambos escritores subrayan el choque a toda velocidad de las "temporalidades locales que permean el espacio-tiempo mecanizado del viaje" (p. 85) y es por ello que prefieren menos la postal turística que la errancia capaz de develar "la cosa real" (p. 91).

Si todo el armazón argumental del libro de Andermann recurre para su desarrollo a una serie de preguntas, el segundo capítulo titulado "Elementos naturales: arquitectura, jardín, modernidad” no es la excepción. Sus diferentes apartados hacen las veces de respuesta a lo siguiente: "¿por qué no hacerle a un edificio o a un parque las preguntas que le haríamos a un poema o un cuadro?” (p. 141). A partir del viaje sudamericano de Le Corbusier en 1929, el autor profundiza en las conexiones entre formas cosmopolitas y naturaleza local tanto en la arquitectura como en el diseño de los jardines. El punto de partida de semejante aspiración teórica redunda en la exploración de los jardines de Victoria Ocampo en sus casas de Mar del Plata, Palermo y San 
Isidro, ese "triángulo de sitios" (p. 111) que funcionaba como caja de resonancia de las tareas de traducción culturales que llevaba adelante la revista Sur. Andermann señala cómo dicho espacio natural, entendido como "otra de las figuraciones de la máquina cultural construida por Ocampo" (p. 114), desplaza la injerencia del jardín de la vanguardia modernista al supeditarlo a los efectos de un jardín de la vanguardia criollista, proclive a la reconstrucción de un tiempo de la infancia y de la geografía del barrio, que no por ello menosprecia una "acomodación de lo foráneo" en lo que a especies vegetales se refiere al desaconsejar el "indigenismo botánico" (p. 118). Se trata de una modernización de los espacios verdes atenta no sólo a la introducción de elementos cosmopolitas como máxima aspiración sino también, a través de su "poder proustiano" (p. 114), a su capacidad de reconstrucción de la memoria familiar, trazando así un puente entre el pasado nostálgico y un presente atravesado por las ansias de lo moderno. Estos elementos complementarios se mantienen presentes en las intervenciones arquitectónicas dedicadas a la "parquización" (y monumentalización) del paisaje (p. 123). Alejandro Bustillo busca domesticar la naturaleza mediante una "épica del ocio" (p. 126) sostenida por la importación de modelos paisajísticos provenientes de los Alpes europeos y los parques nacionales de Estados Unidos y Canadá junto con una "apropiación modernizante" (p. 139) de elementos asociados con las poblaciones indígenas. De esta manera, a través de la "conquista de la frontera por el turismo" (p. 140), el paisaje patagónico deviene panorama y aúna en su centro un modernismo arquitectónico en clave aristocratizante, tal y como lo demuestra la construcción del Hotel Llao Llao en Bariloche o incluso el proyecto de jardín de Luis Barragán en México. Sus diseños botánicos se organizan como un "refugio del ruralismo politizado del sexenio cardenista” (p. 157). Esta idealización del paisaje-jardín, tanto en El Cabrío así como en El Pedregal, barrios aledaños al D.F, destaca la ensoñación del paseante solitario que se rebela ante el trazado urbano estriado por el paisajismo decimonónico: un "jardín-escenario diseñado menos para ser habitado que para ser contemplado desde el otro lado de la gran ventana-visor” (p. 159). En contraposición con la jardinería individualizante de Barragán aunque coincidiendo en su diálogo con la dimensión de profundidad propia de la arquitectura modernista, Roberto Burle-Marx inventa "formas de convivencia entre plantas y hombres" (p. 161) al incorporar "en su propio proceso creativo las dos grandes series de la tradición moderna del paisaje: la exploración espacial del viajero y el gesto localizador del jardinero: el paisaje in visu y el paisaje in situ" (p. 169). Al entender el parque público de Burle Marx como un dispositivo pedagógico propio del Estado desarrollista, Andermann resalta la reconversión de su sentido ya que en la actualidad los jardines exponen una "violencia inscrita en lo viviente mismo" (p. 173) que buscaba contenerse mediante estos diagramas arquitectónicos y que emergió en las narraciones regionalistas de comienzos de siglo.

En este sentido, el "capítulo bisagra" (p. 28) de Tierras en trance titulado "La naturaleza insurgente", el tercero según el ordenamiento del índice, retoma dicha descripción de un ejercicio de la violencia de y contra la naturaleza en los paisajes selváticos. Las diferentes reescrituras del núcleo narrativo protagonizado por Anaconda en los cuentos de Horacio Quiroga a partir de la revisión de una "alianza animal" (p. 185) busca la instalación de una biopolítica oposicional basada en la comunidad de lo viviente, capaz de resistir la catástrofe del capitalismo extractivista en dicho territorio a la vez que promueve un corrimiento de la frontera que la separa cada vez más de lo humano. En relación con este tema, Andermann subraya las relaciones de reciprocidad entre las serpientes y los mensú en tanto instancia discursiva propiciatoria para la creación de un perspectivismo transespecie. De la misma manera, al enfocarse en el noroeste argentino, Andermann se detiene en los ensayos de Bernardo Canal Feijóo y de Orestes Di Lullo y en cómo sus objetos de estudio redundan en la aparición del obraje destinado al trazado de las líneas de ferrocarril como si fuera un "dispositivo de producción capitalista fronterizo" (p. 207) que carcome el paisaje. Tanto Canal Feijóo en su Ensayo sobre la expresión popular artistica en Santiago o en De la estructura argentina así como Di Lullo en El bosque sin leyenda: ensayo económico-social supeditan su visión de la Historia a los alcances del terreno como aspecto determinante. En tanto punto de contacto de ambas propuestas de análisis, Andermann insiste en la injerencia de un concepto como el de "despaisamiento" (p. 216): un neologismo capaz de ilustrar una historia natural del antropoceno a partir de los efectos devastadores del extractivismo en la provincia de Santiago del 
Estero. El capítulo cierra con la yuxtaposición entre el paisaje selvático y las reflexiones acerca de la guerrilla en La montaña es algo más que una inmensa estepa verde de Omar Cabezas y Los días de la selva de Mario Payeras. Uno y otro de estos textos muestra un abordaje del paisaje entendido como "pharmakon selvático" ya que es factible su interpretación en clave "inmuno-lógica" (p. 224): los testimonios de la guerra de guerrilla recuperan del venenoso modelo narrativo de la novela de la selva esbozado por el proyecto liberal un esquema ficcional capaz de repeler su carga viral. El "proyecto inmunológico de la guerrilla" (p. 246) muestra cómo en los testimonios de la resistencia revolucionaria el ambiente natural se torna una zona liminal en donde se pasa de la alianza inmunitaria entre especies descripta más arriba a la idea de la communitas selvática en tanto grado cero del proyecto político de la guerrilla.

Luego de este punto de inflexión en su estudio, Andermann señala la manera en que sus gestos críticos se alejan de la transversalidad como forma de aproximación al corpus y, a partir del cuarto capítulo, que lleva por título "El giro ambiental: del marco al medio", el soporte de sus elucubraciones va a estar en el material mismo de las obras a partir de un "salto del paisaje al ambiente", el cual enfatiza en la "co-incidencia entre una práctica experimental/ proposicional y el lugar que esta práctica co-funda” (p. 254) validando así la pulsión creativa entendida como recreación de un lugar. El relevamiento de las "manifestaciones ambientales" (p. 258) presentes en la trayectoria artística de Hélio Oiticica se despliegan a partir del cuerpo "abstracto y virtual proyectado como modalidad kinética-participante" (p. 261) tal y como sucedía en Tropicália para desembocar, tiempo después, en un proceso artístico atravesado primero por un "ethos exílico" (p. 276) a partir de su estadía en Nueva York y luego, a su regreso, mediante sus tentativas por re-emplazar dichas ideas en el basural de Cajú. Este proceso de ampliación del trabajo estético de Oiticica, el cual pasa de lo corporal a lo arquitectónico, se distancia de los planteos del grupo Amereida ya que, donde Oiticica encontraba una "ética exílica del mundo-abrigo", fundamental para su proyecto creador, dicha comunidad de artistas se pliega hacia un "encierro solipsista" (p. 292). Basado en la exploración de las relaciones entre arquitectura y poesía mediante una "colectivización de la poiesis" (p. 296) identificable en proyectos como el de la Ciudad Abierta en las cercanías de Viña del Mar, este grupo de artistas lleva a cabo diferentes travesías con el objetivo de elaborar un mapa poético del territorio capaz de mostrar, como factor determinante del "trance de la representación" (p. 301) al que sucumben, el carácter inconmensurable de lo circundante. La falta de injerencia de la "exterioridad social” (p. 307), noción acuñada por Nelly Richards a propósito del arte postdictatorial en Chile, en el plan de acción del grupo Amereida "iba a contramano" (p. 303), sostiene Andermann, de un proceso artístico que indagaba en la potencialidad del acto político revolucionario. En este punto el capítulo se organiza, otra vez, alrededor de una pregunta acerca de lo que surge en "la aproximación de la práctica artística con el activismo sindical y campesino, con el público de los medios masivos o con los habitantes de los márgenes urbanos" (p. 323). Para ilustrar esta salida del arte a la calle, Andermann se detiene tanto en las acciones del grupo CADA así como en las de Tucumán Arde, pasando revista al traslado de las relaciones entre paisajes in situ e in visu "de la pintura y la jardinería a lo foto-cinematográfico y a la instalación y lo teatral” (p. 309). Específicamente, las acciones llevadas adelante por ese grupo de artistas porteños, santafecinos y rosarinos tenían como objetivo, sostiene el autor, la "apertura de un espaciotiempo experimental" capaz de cristalizar una "trama de lucha compartida" (p. 321) aunque sin incorporar como protagonistas a los interlocutores del "mundo de pobreza y alteridad étnica" al que se referían en sus propuestas artísticas. Este límite, sostiene Andermann, ejemplifica la imposibilidad del giro ambiental por sumar un mensaje político a nivel del significante. Quizás una apuesta estética diferente se encuentra en la obra de Ana Mendieta, cuyo análisis se liga en la siguiente sección de este capítulo no tanto por su impronta migrante sino más bien con parte de "una constelación en función de la cual pueda desplegar sentidos nuevos" (p. 334) a partir de su acercamiento a la órbita del giro ambiental en Latinoamérica. El uso de la tierra como soporte de sus prácticas artísticas puede entenderse como actualización de las instancias de duelo producto de las dictaduras del Cono Sur y, de la misma manera, como acción combinatoria de cuerpo y ambiente en virtud de la desconfiguración de una "biopolítica imperial que ha hecho redundante 
la separación entre figura y fondo sobre la que estaba organizado el régimen extractivo anterior, manifestado estéticamente en la forma paisaje" (p. 335).

El último capítulo de Tierras en trance lleva como título "Después de la naturaleza: memorias, derivas, transmutaciones". Su intención es desandar las aproximaciones al paisaje como ordenamiento autosuficiente y cohesivo de un "ambiente natural" destinada a "naturalizar la violencia pasada y así también a encubrir bajo una coherencia imaginística engañosa las violencias presentes" (p. 341). Con este fin, Andermann analiza las "visiones perturbadoras" que se desprenden de "ciertas zonas de las neorregionalistas del cine latinoamericano” (p. 342). Así, la inerte monumentalización del duelo edificada por los parques de la memoria en nuestro país y en Chile le sirve a Andermann como ejemplo opuesto al flujo temporal y espacial que sostiene la "experiencia errante" (p. 356) de ese mismo duelo en filmes como Papá Iván de María Inés Roqué, Los rubios de Albertina Carri o (b)istorias cotidianas de Andrés Habegger. A estas prácticas cinematográficas disidentes se suman otras como Los salvajes de Alejandro Fadel, Los muertos de Lisandro Alonso, Serras da Desordem de Andrea Tonacci, La rabia de Albertina Carri o La ciénaga de Lucrecia Martel, en donde personajes al borde de la "in-comunicación" e instalados en un "in-mundo" (p. 386) hacen que la infancia del lenguaje no sólo ordene la narración sino también que funcione como "un puro conducto de violencia", capaz de socavar no sólo las "coordenadas espacio-temporales del cine cartográfico" (p. 379) sino también el límite entre lo humano y lo animal. La mudez de los sujetos frente a la cámara trae a colación, por tanto, la manera en que el entorno material abandona sus rasgos paisajísticos "como presencia de un Real" y deviene el fondo de la acción de un personaje sumido en una "vida precaria” (p. 390). En la sección final del capítulo Andermann investiga las relaciones entre el laboratorio y el atelier como fundamentos de los "discursos inespecíficos" (p. 400) del bioarte y el arte ecológico en las obras de Luis Fernando Benedit, Andrea Juan, Louise Ganz, Ursula Biemann y Paulo Tavares. Se trata de formas del ensayo destinadas a "reensamblar los géneros, procedimientos y regímenes de captura, administración e intervención de lo viviente" a partir de la importancia dada al "entorno no humano como archivo latente" (p. 412) capaz de funcionar como material para agendas subalternas.

Vale la pena destacar, a modo de reflexión final, la manera en que sobrevuela la lectura de Tierras en trance la posibilidad de interrumpir el desarrollo de las ideas mediante un apéndice visual que reproduce las obras analizadas. La alternancia entre ambas prácticas no solo potencia la articulación entre el discurso teórico-crítico (que roza por momentos el tratado estético) y el artístico sino que también expone el propio método de lectura del autor, quien al seleccionar este bagaje de instalaciones, pinturas, poemas, novelas y films, deja en claro que lo suyo es también la construcción de un canon alternativo de la modernidad estética latinoamericana. No tanto porque funcione como puesta en crisis de la institución arte y sus criterios de selección sino más bien porque en esas prácticas artísticas hay una yuxtaposición entre lo político, lo económico, lo social y lo ecológico que les permite escabullirse de la categoría tradicional de obra. 